'toddler diarrhoea' when given apple juice or other fruit drinks containing sorbitol. ${ }^{6}$

The incidence of clinical fructose malabsorption is uncertain. Rumessen and Gudmand-Hoyer showed that eight of 10 healthy adult volunteers failed to absorb $50 \mathrm{~g}$ of fructose, but only one of 10 failed to tolerate $15 \mathrm{~g}$. They all absorbed $100 \mathrm{~g}$ of sucrose or a mixture of $50 \mathrm{~g}$ fructose and glucose. None had symptoms related to their malabsorption. ${ }^{2}$ In a further study they showed malabsorption of fructose in seven of 10 adult volunteers who were given $5 \mathrm{~g}$ of fructose and sorbitol concurrently. ${ }^{5} \mathrm{~A}$ connection between irritable bowel syndrome' and fructose malabsorption has also been proposed. The same authors studied the absorptive capacity of 25 patients with functional bowel symptoms aged between 31 and 77 years, and found that 13 of the 25 showed abnormal breath hydrogen peaks and symptoms after taking $25 \mathrm{~g}$ fructose. ${ }^{3}$ The symptoms were made worse by the addition of sorbitol, but there was no reaction to sucrose or sorbitol alone.

Fructose intolerance-reproducible unpleasant symptoms in response to an oral challenge-does not therefore always follow fructose malabsorption. Our patient had both malabsorption and intolerance of fructose but tolerated glucose. The child clinically tolerated sucrose, but showed an intermediate degree of sucrose absorption on breath hydrogen testing. Presumably the normal sucrase activity hydrolysed the disaccharide and liberated free glucose, which then facilitated fructose transport (as was shown in studies in adults). ${ }^{2}$ This suggests that the low capacity oxygen dependent transport system was defective in our patient.

Abdominal colic and chronic non-specific diarrhoea are common complaints in infancy and childhood. One similar case of diarrhoea secondary to fructose malabsorption has previously been described, but the diagnosis was not recognised until the age of 12 years, although the symptoms began in early childhood as did those of our patient. ${ }^{4}$ The apparently high incidence of this condition in adults, and its possible relevance to 'functional' bowel symptoms suggest that it should be more actively considered in children with these symptoms, especially if they follow the ingestion of fruits or fruit juices.

We thank Professor RDG Milner for permission to report this case, Dr CD Holdsworth and Dr PT Hardcastle for suggestions concerning the investigations, Dr T Cox for helpful comments and assay of intestinal fructaldolase activities, and Dr GL Barnes for further information about the previously reported childhood for fure.

1 Gracey M, Burke V, Oshin A. Intestinal transport of fructose. Lancet 1970; ii:827-8.

2 Rumessen JJ, Gudmand-Hoyer E. Absorption capacity of fructose in healthy adults. Comparison with sucrose and its constituent monosaccharides. Gut 1986;27:1161-8

3 Rumessen JJ, Gudmand-Hoyer E. Functional bowel disease malabsorption and abdominal distress after ingestion of fructose, sorbitol, and fructose-sorbitol mixtures. Gastroenterology 1988;95:694-700.

4 Barnes G, Mc Kellar W, Lawrance S. Detection of fructose malabsorption by breath hydrogen test in a child with diarrhea. I Pediatr 1983;103:575-7.

5 Rumessen JJ, Gudmand-Hoyer E. Malabsorption of fructose sorbitol mixtures. Interactions causing abdominal distress. Scand f Gastroenterol 1987;22:431-6.

6 Hyams JS, Etienne NL, Leichtner AM, Theuer RC. Carbohydrate malabsorption following fruit juice ingestion in young children. Pediatrics 1988;82:64-8.

\title{
Dietary management of D-lactic acidosis in short bowel syndrome
}

\section{Institute of Child Health, University of Birmingham and The Children's Hospital, Birmingham A J Mayne D J Handy $M$ A Preece R H George I W Booth Correspondence to: Dr I W Booth Institute of Child Health, Francis Road, Birmingham B16 8ET.} Accepted 26 October 1989

A J Mayne, D J Handy, M A Preece, R H George, I W Booth

\begin{abstract}
Manipulation of carbohydrate intake was used to treat severe, recurrent D-lactic acidosis in a patient with short bowel syndrome. Dietary carbohydrate composition was determined after assessment of D-lactic acid production from various carbohydrate substrates by faecal flora in vitro. This approach may be preferable to repeated courses of antibiotics.
\end{abstract}

D-lactic acidosis is a well recognised, but rare, complication of short bowel syndrome and intestinal bypass surgery. ${ }^{12}$ To date, seven children have been reported in whom this disorder occurred as a complication of short bowel syndrome. Non-absorbed carbohydrate is fermented by colonic organisms, but lactobacilli when present, unlike most other bacteria, produce D-lactic acid, which cannot be metabolised by D-lactate dehydrogenase. Absorption leads to a severe metabolic acidosis. Treatment has been directed at altering the colonic flora with antibiotics, ${ }^{2} 3$ or by administering a standard bacterial flora orally. ${ }^{3}$

Recently we have successfully treated a girl with this disorder by dietary carbohydrate manipulation alone.

\section{Case report}

After massive small bowel resection for a spontaneous small intestinal volvulus, which followed a vigorous session of disco dancing, a 9 year old girl was left with $14 \mathrm{~cm}$ of jejunum beyond the duodenojejunal flexure; the ileocaecal valve was preserved. After prolonged parenteral nutrition she was discharged nine months later on a normal diet together with energy supplements given as sip feeds. 
Results of fermentation tests of faecal lactobacilli: concentrations of $D$-lactate and bromocresol purple reaction*

\begin{tabular}{|c|c|c|c|c|c|c|c|c|}
\hline \multirow{2}{*}{$\begin{array}{l}\text { Carbohydrate } \\
\text { source }\end{array}$} & \multicolumn{2}{|l|}{ Strain 1} & \multicolumn{2}{|l|}{ Strain 2} & \multicolumn{2}{|l|}{ Strain 3} & \multicolumn{2}{|l|}{ Strain 4} \\
\hline & $\begin{array}{l}\text { D-lactate } \\
\text { (mmol/l) }\end{array}$ & $\begin{array}{l}\text { Bromocresol } \\
\text { purple } \\
\text { reaction }\end{array}$ & $\begin{array}{l}\text { D-lactate } \\
(\mathrm{mmol} / \mathrm{l})\end{array}$ & $\begin{array}{l}\text { Bromocresol } \\
\text { purple } \\
\text { reaction }\end{array}$ & $\begin{array}{l}\text { D-lactate } \\
(\text { mmolll })\end{array}$ & $\begin{array}{l}\text { Bromocresol } \\
\text { purple } \\
\text { reaction }\end{array}$ & $\begin{array}{l}\text { D-lactate } \\
(\text { mmolll })\end{array}$ & $\begin{array}{l}\text { Bromocresol } \\
\text { purple } \\
\text { reaction }\end{array}$ \\
\hline Glucose & 27 & + & 27 & + & 141 & + & 82 & + \\
\hline Sucrose & 17 & + & 34 & + & 92 & + & $\begin{array}{l}02 \\
87\end{array}$ & + \\
\hline Fructose & 15 & + & 34 & + & 92 & + & 66 & + \\
\hline Raffinose & 15 & + & 6 & - & 2 & - & 34 & + \\
\hline Lactose & 23 & + & 27 & + & 66 & + & 51 & + \\
\hline Maltose & 23 & + & 97 & + & 102 & + & 51 & + \\
\hline Arabinose & 6 & - & 6 & - & 7 & - & 6 & - \\
\hline Inositol & 1 & - & 1 & - & 1 & - & 1 & - \\
\hline Xylose & 11 & - & 8 & - & 12 & - & 46 & + \\
\hline Sorbitol & 1 & - & 2 & - & 2 & - & 2 & - \\
\hline Starch & 1 & - & 71 & + & 77 & + & 61 & + \\
\hline Base & 1 & - & 2 & - & 1 & - & 1 & - \\
\hline
\end{tabular}

Bromocresol purple reaction: positive $(+)$ and negative $(-)$.

Six months later, after visiting a funfair and eating large amounts of sucrose rich foods, she presented with severe ataxia, slurred speech, and confusion. Biochemical investigations showed a severe metabolic acidosis (hydrogen ion concentration $80 \mathrm{nmol} / \mathrm{l}$, carbon dioxide pressure $2 \cdot 3 \mathrm{kPa}$, and bicarbonate $8 \mathrm{mmol} / \mathrm{l}$ ) with a high plasma $\mathrm{D}$-lactate concentration $(\mathbf{9} \cdot 1$ $\mathrm{mmol} / \mathrm{l}$; normally not detected); L-lactate was normal $(1 \cdot 1 \mathrm{mmol} / 1$; normal range $0 \cdot 6-2 \cdot 2)$ and ethanol not detected. She was treated with intravenous sodium bicarbonate and recovered rapidly.

During the next year she had several identical episodes that were related to eating large amounts of sucrose. Eighteen months after her operation episodes were occurring two to three times per month and she was exhibiting growth failure.

Nutritional support was provided by a whole protein feed (delivered nasogastrically by continuous infusion) in which the carbohydrate was provided as glucose oligosaccharides (Isocal, Mead Johnson). Increasing the enteral feed to provide more than $30 \%$ of her energy requirement, however, again resulted in D-lactic acidosis.

Stool culture showed a pure growth of lactobacilli, but treatment with a variety of broad spectrum oral antibiotics was ineffective. This led us to investigate the D-lactate producing capabilities of her colonic flora in relation to various carbohydrate substrates in vitro, with a view to manipulating her dietary carbohydrate.

\section{Methods}

Two species of lactobacilli (Lactobacillus fermentum and Lactobacillus acidophilus) were identified in the patient's stool. Their ability to produce acid from different carbohydrate substrates was assessed in DeMan, Rogosa, and Sharpe's (MRS) lactobacillus broth ${ }^{4}$ in the presence and absence of a variety of carbohydrates $(20 \mathrm{~g} / \mathrm{l})$. After incubation at $37^{\circ} \mathrm{C}$ for 48 hours, pH was tested with $2 \%$ bromocresol purple. Acid production was deemed to be present if the solution turned yellow $(\mathrm{pH}<6)$. Both organisms isolated from our patient fermented glucose, lactose, maltose, and sucrose, but there was no acid production from starch.

Further studies were undertaken to confirm that acid production in our test did indeed reflect the ability of lactobacilli to produce D-lactic acid from differing carbohydrate substrates.

Four different species of lactobacilli, including those of the patient, were therefore cultured as before, and the $\mathrm{pH}$ tested after 48 hours. After a further five days incubation, cultures were filtered and analysed blind for D-lactic acid using an enzymatic kit for L-lactate determination, substituting D-lactate dehydrogenase for L-lactate dehydrogenase (Boehringer Mannheim).

\section{Results}

The results are shown in the table. Concentrations of D-lactate up to $141 \mathrm{mmol} / \mathrm{l}$ were obtained. A positive bromocresol purple reaction was present after 48 hours incubation in all solutions in which the D-lactic acid concentrations exceed $14 \mathrm{mmol} / \mathrm{l}$ at seven days, with no false positives or negatives. This confirmed that the bromocresol purple reaction was a valid screen for D-lactic acid production by lactobacilli.

\section{DIETARY MANIPULATION}

Our investigations confirmed the absence of D-lactate production from starch by the patient's Lactobaccillus spp. The diet was therefore altered, such that carbohydrate was provided mainly in polymeric form, using Osmolite (Abbott Laboratories) as a nasogastric tube feed. This resulted in a dietary carbohydrate profile as follows: monosaccharide $1 \%$, disaccharide $6 \%$; trisaccharide $8 \%$, tetrasaccharide $7 \%$, and pentasaccharide (and above) $78 \%$.

In the subsequent 30 months there have been no further episodes of D-lactic acidosis and no antibiotic treatment. Growth has resumed and the patient has remained well in full time education.

\section{Discussion}

D-lactic acidosis should be suspected in any patient with short bowel syndrome with recurrent acidosis, particularly when complicated by abnormal neurological signs. In 1983 Perlmutter et al showed that a reduction in dietary carbohydrate in children with short gut syndrome led to a reduction in plasma D-lactate 
concentration. ${ }^{1}$ Dahlquist et al were able to precipitate an episode of $\mathrm{D}$-lactic acidosis in a patient with intestinal bypass surgery, by using a $25.08 \mathrm{MJ}(6000 \mathrm{kcal})$ load containing $54 \%$ carbohydrate. ${ }^{5}$ Similarly, Rosenthal and Pesce described a recurrence of abnormal neurological signs, together with high D-lactate concentrations, in a patient in whom enteral feeds were substantially increased. ${ }^{6}$

Our studies show the importance of the nature of the dietary carbohydrate substrate in the production of D-lactic acidosis. Manipulation of dietary carbohyrate with strict control of monosaccharides and oligosaccharides was successful in our patient and preferable to repeated courses of broad spectrum antibiotics, which may alter the colonic flora in such a way as to impair valuable colonic salvage of nonabsorbed nutrients.

1 Perlmutter DH, Boyle JT, Campos JM, Egler JM, Watkins JB. D-lactic acidosis in children: an unusual metabolic complication of small bowel resection. $\mathcal{F}$ Pediatr 1983;102: 234-8.

2 Carr DB, Shih VE, Richter JM, Martin JB. D-lactic acidosis stimulating a hypothalmic syndrome after bowel by-pass. Ann Neurol 1982;11:195-7.

3 Schoorel EP, Giesberts MAH, Blow M, Van Gelderen HH. D-lactic acidosis in a boy with short bowel syndrome. Arch Dis Child 1980;55:810-2.

4 Dunlop RH, Hammond PB. D-lactic acidosis of ruminants. Ann NY Acad Sci 1965;119:1109-32.

5 Dahlquist NR, Perrault J, Callaway CI, Jones JD. D-lactic acidosis and encephalopathy after jejunoileostomy: response to overfeeding and to fasting in humans. Mayo Clin Proc 1984;59:141-5.

6 Rosenthal P, Pesce M. Long-term monitoring of D-lactic acidosis in a child. $\mathcal{f}$ Pediatr Gastroenterol Nutr 1985;4: $674-6$.

\title{
Atopic eczema, hyponatraemia, and hypoalbuminaemia
}

\author{
H M Goodyear, J I Harper
}

\begin{abstract}
We describe an infant with atopic eczema, treated with homoeopathic medicines, who presented with erythema and limb oedema. Concentrations of urinary and plasma sodium and plasma albumin were low. On conventional treatment he made a satisfactory recovery.
\end{abstract}

Atopic eczema affects $5-10 \%$ of children under the age of 5 years. ${ }^{1}$ We report an infant with atopic eczema, treated inappropriately with homoeopathic medicines, who became seriously ill with deterioration of the eczema and associated metabolic complications.

\section{Case report}

A 6 month old boy presented to casualty with a one week history of generalised erythematous weeping skin and pronounced oedema of the limbs. His parents had refused hospital admission when seen four days previously. Since 1 month of age his skin had been dry and eczematous. Homoeopathic medicines were prescribed for his eczema by a registered homoeopath. The eldest of his three brothers who had mild eczema in infancy had received similar treatment. Conventional treatment was repeatedly declined by the family, apart from a one week hospital admission at 4 months of age with bronchiolitis and eczema. He had received nine different homoeopathic medicines before admission including a six centesimal $\left(10^{-12}\right)$ dilution of trace metals (iron and arsenic).

Biochemical investigations showed low plasma and urinary sodium concentrations of
$121 \mathrm{mmol} / \mathrm{l}$ and $10 \mathrm{mmol} / \mathrm{l}$ respectively and a low plasma albumin of $11 \mathrm{~g} / 1$ (no proteinuria). Activities of liver transaminases and alkaline phosphatase and concentrations of plasma urea and potassium were normal.

Treatment was given with $0.45 \%$ sodium chloride solution, repeated albumin infusions, and intravenous flucloxacillin and benzylpenicillin. Intensive local skin care was started with potassium permanganate baths twice daily. Initially an ointment containing $1 \%$ hydrocortisone and 3\% clioquinol (VioformHydrocortisone; Ciba) was applied and then changed to one containing $0.0125 \%$ flurandrenolone and 3\% clioquinol (Haelan C; Dista) applied twice daily to affected areas. A cream containing $1 \%$ hydrocortisone and $2 \%$ miconazole nitrate (Daktacort; Janssen) was applied three times daily to the perineum, and Diprobase cream moisturiser (Kirby-Warrick) was used on all areas of the body every two hours. Skin swabs initially grew Staphylococcus aureus and $\beta$ haemolytic Streptococcus Lancefield group A. Repeat swabs also grew klebsiella and Escherichia coli and thus the antibiotics were changed to ceftazidime and gentamicin.

The weeping, erythema, and oedema of his skin gradually subsided and progress was satisfactory, apart from an episode of rotavirus gastroenteritis. He was discharged after three weeks with normal plasma sodium and albumin concentrations. On review at 10 months of age, he is thriving with mild eczema, which is now maintained on daily baths using an additive containing $5 \%$ acetylated wool alcohols and $63 \cdot 7 \%$ liquid paraffin (Oilatum Emollient; Stiefel), 1\% hydrocortisone ointment, and Diprobase

cream.
Correspondence to: Dr Harper

Accepted 18 October 1989 